UDC 316.42

LBC 60.59

\title{
FREELANCE AS A MODERN FORM OF EMPLOYMENT IN THE LABOR MARKET IN SOCIO-ECONOMICSPACE OFTHE CITY ULYANOVSK
}

\author{
Marina I. Kadnichanskaya \\ Ulyanovsk State University, Ulyanovsk, Russian Federation \\ Elena P. Galkina \\ Ulyanovsk State University, Ulyanovsk, Russian Federation
}

\begin{abstract}
Today in the world, the prevalence of information and telecommunication technologies (ICT) and the Internet contribute to the development of new strategies for work behavior among the population, when less formal rules are applied. This leads to the expansion of the socio-economic space of the city beyond the geographical territory. In modern society, there is a rapid development of the service sector. The introduction of modern technology allows the use of a variety of employment models. The number of temporary workers in the organization's staff is increasing. The development of informal employment and self-employment has resulted in freelance as a new model of employment in the labor market. Unwillingness to work in an office with set hours, search for freedom in allocation of time and work, an increased interest in new technologies, are the reasons for choosing freelance as a labor strategy for young people. The article analyzes the work of domestic and foreign researchers and official statistics in the field of labor and employment. The methodological basis of the study was an online survey of 300 respondents employed in freelance and living in the city of Ulyanovsk, conducted in February-April 2018. For the analysis of empirical data, the IBM SPSS Statistics program was used. The study identified the features of freelancing in the modern labor market in the socio-economic space of the city of Ulyanovsk, revealed the degree of youth involvement in the freelance sphere, the motives for choosing freelancing as a labor strategy, described the current problems and risks faced by freelancers. The hypothesis is confirmed that the spread of freelance as a new model of employment in the labor market is due to the transformation of labor and employment processes, as well as due to the development of information and communication technologies, in particular the Internet, which allows individuals to work outside the office.
\end{abstract}

Key words: labor market, employment, freelance, socio-economic space of the city, youth.

УДК 316.42

ББК 60.59

\section{ФРИЛАНС КАК СОВРЕМЕННАЯ ФОРМА ЗАНЯТОСТИ НА РЫНКЕ ТРУДА В СОЦИАЛЬНО-ЭКОНОМИЧЕСКОМ ПРОСТРАНСТВЕ Г. УЛЬЯНОВСКА}

\author{
Марина Ивановна Кадничанская \\ Ульяновский государственный университет, г. Ульяновск, Российская Федерация \\ Елена Петровна Галкина \\ Ульяновский государственный университет, г. Ульяновск, Российская Федерация
}

Аннотация. Сегодня в мире распространенность информационно-коммуникационных технологий (далее - ИКТ) и сети Интернет способствуют выработке новых стратегий трудового поведения у населения, в которых применяется все меньше формальных правил. Это приводит к выходу социально-экономического 
пространства города за рамки географической территории. В современном обществе происходит стремительное развитие сферы услуг. Внедрение современных технологий позволяет использовать разнообразные модели занятости. Количество временных работников в штате организации увеличивается. Развитие неформальной занятости и самозанятости приводит к появлению фриланса как новой модели занятости на рынке труда. Нежелание работать в офисе со стабильным графиком, стремление к свободе в распределении времени и нагрузки, повышенный интерес к новым технологиям становятся причинами выбора фриланса как трудовой стратегии именно молодежью. В статье проанализированы работы отечественных и зарубежных исследователей в области труда и занятости; проведен анализ официальных статистических данных. Методическую основу исследования составил опрос методом онлайн-анкетирования 300 респондентов, занятых во фрилансе и проживающих в г. Ульяновске, проведенный в феврале-апреле 2018 года. Для анализа эмпирических данных использовалась программа IBM SPSS Statistics. В ходе исследования определены особенности фриланса на современном рынке труда в социально-экономическом пространстве г. Ульяновска, выявлены степень включенности молодежи в сферу фриланса, мотивы выбора последнего как трудовой стратегии, описаны актуальные проблемы и риски, с которыми сталкиваются фрилансеры. Подтверждена гипотеза о том, что распространение фриланса как новой модели занятости на рынке труда происходит вследствие трансформации процессов труда и занятости, а также благодаря развитию информационно-коммуникационных технологий, в частности, сети Интернет, позволяющей индивидам работать вне офиса.

Ключевые слова: рынок труда, занятость, фриланс, социально-экономическое пространство города, молодежь.

\section{Введение}

За последние двадцать лет в условиях глобализации заметно изменился мировой рынок интеллектуального труда. В современном обществе происходят изменения, характеризующиеся неопределенностями и рисками. Такие перемены не имеют ясных последствий и заранее прогнозируемых результатов. Социально-экономическое пространство современных городов выходит за свои географическотерриториальные границы. В нем осуществляются формальные и неформальные взаимодействия различных групп в рамках своих экономических интересов (обладающих определенными капиталами, но не привязанных к определенной территории). Помимо этого, с использованием современных технологий по-новому выстраиваются и практики их взаимодействия [Данилова 2016, 179].

Появление нестандартных форм занятости в эпоху постиндустриализма обусловило востребованность в работе, которая требует знаний по обработке и производству информации, ведению разного рода проектов, что влечет за собой использование временных работников без предоставления офисного рабочего места. Одним из примеров произошедших за последнее десятилетие изменений в российском обществе является распространение фриланса как новой модели занятости.

\section{Обзор литературы}

До 60-х гг. ХХ в. процессы, протекающие в социально-трудовой сфере, были основой для разработки общесоциологических теорий общества модерна (М. Вебер, Э. Дюркгейм, К. Маркс и др.).

К. Маркс в своей теории отчуждения труда рассматривал труд как нечто внешнее, не принадлежащее сущности рабочего, в нем человек не чувствует себя счастливым и свободным. В данном процессе человек является как бы «оторванным» от самого себя, поэтому только вне труда он может быть самим собой [Маркс 1956, 563].

По мнению французского социолога Э. Дюркгейма, разделение общественного труда обеспечивает единство современного капиталистического общества. Индивидуализация сознания под воздействием процесса разделения труда приводит к усилению чувства изолированности человека и увеличению социальной дистанции. Решить эту проблему возможно с помощью профессиональных объединений, что и способствует созданию новых моделей отношений. Указывая на противоречия между трудом и капиталом, Э. Дюркгейм отмечает, что для большинства людей упорный труд это невыносимая повинность [Дюркгейм 1996, 225]. Принуждение составляет неравенство во внешних условиях борьбы. Только при достижении органической солидарности можно это- 
го избежать, но стороны должны находиться в равных условиях.

Немецкий социолог М. Вебер в своих работах показывает, что положение индивида в системе производства определяется способами его заработка и классовым местом, которое он занимал в обществе. Он делает акцент именно на занятости индивида, которая влияет на статус и положение в обществе [Вебер 2012, 51]. По М. Веберу, возможности в рыночных отношениях зависят от количества и качества тех ресурсов, которыми обладает каждый индивид. Такими, помимо средств производства, являются знания и технологии. Он считал, что освобождение рабочих будет являться важнейшим критерием достоверного определения затрат при производстве. По его мнению, это должно позволить рабочим самостоятельно распоряжаться собственным трудом. Следовательно, только при рационализации производства и при обеспечении рациональных технологий и правовых норм становится возможным наемный труд.

Немаловажной в рассмотрении труда и занятости является стратификационная модель, разработанная американским социологом Л. Уорнером, в которой он отмечал, что в обществе существуют и другие факторы, помимо профессии и богатства, которые оказывают влияние на статус индивида. Но эта классовая система гарантирует детям с момента рождения социальный статус их родителей. Однако, несмотря на существующие разные права и привилегии у высших и низших классов, в классовом обществе возможна социальная мобильность, то есть перемещение по социальной лестнице [Уорнер 1999, 43].

Анализ трансформации процессов в сфере труда в современном обществе представлен в теориях постиндустриального общества (О. Тоффлер, Д. Белл и др.) и общества постмодерна (3. Бауман, Ж. Бодрийяр и др.). В их рамках исследователи рассмотрели вопросы трансформаций социокультурных оснований в трудовой деятельности и в системе занятости.

Изучая природу наемного труда, 3. Бауман отмечал, что произошедшие изменения в современном обществе связаны со сменой долгосрочной ментальности на краткосрочную [Бауман 2005, 28].
Согласно концепции «трех волн» Э. Тоффлера в супериндустриальном обществе происходит активное развитие ИКТ, что влечет за собой сокращение монотонного труда и вынесение физического места работы за границы офиса. Ученый применяет термин «электронный коттедж», показывая широкие возможности работы вне офиса с гибким графиком [Тоффлер 2004].

Испанский социолог М. Кастельс в своих работах рассматривает новый тип общества и называет его информациональным. Происходящая в нем трансформация в сфере труда и занятости знаменуется появлением нового типа субъектов труда - «сетевых» работников и работников с гибким рабочим днем. По мнению социолога, производительность труда зависит от технологии порождения знаний, обработки информации и символической коммуникации [Кастельс 2000, 39]. М. Кастельс описывает возникновение «новой экономики» и электронного бизнеса как результат развития интернета. В информационном обществе постепенно исчезает представление о предсказуемой модели карьерного роста, когда работники, у которых в договоре четко прописаны их права и обязанности, находятся в компании полный рабочий день. С развитием Интернета одним из основных проявлений трансформации трудовых отношений в информационном обществе становится гибкая схема занятости [Кастельс 2004, 85]. Работа на неполный рабочий день, самостоятельная занятость, временная работа в современном обществе принимают более распространенный характер.

Наемные работники как феномен индустриального общества изменили структуру современного социума. В социологической науке под наемными работниками понимаются индивиды, работающие по найму, на основе трудового договора, выполняющие определенную работодателем работу [Задорожная 2011, 79]. Процессы глобализации и череда экономических кризисов привели к тому, что часть наемных работников из стабильно занятых перешла в разряд нестабильно занятых. Фрилансеров относят к нестабильно занятым наемным работникам. Фриланс определяют как вид занятости (самозанятости) на рынке товаров и услуг без заключения долговременного тру- 


\section{НАУЧНЫЕ СООБЩЕНИЯ}

дового договора вне штата организации (удаленно) с низкой степенью зависимости от работодателя [Чаплашкин 2011, 13].

Каждый индивид, достигнув трудоспособного возраста, использует трудовые стратегии вне зависимости от того, работает он на данный момент или нет. Формирование трудовых стратегий происходит посредством определенного представления о желаемом доходе, а также при определенной величине трудовых затрат [Елкина 2007, 89]. Выбор трудовой стратегии происходит, когда молодые люди достигают трудоспособного возраста. Трудовые стратегии молодежи различаются, и это обстоятельство детерминировано как объективными социальными факторами, так и индивидуальными особенностями молодых людей. Стоит отметить альтернативный характер трудовых стратегий молодежи: 1) осведомленной о текущем состоянии рынка труда, а также знает, какая работа ей нужна; 2) не готовой ко вступлению на рынок труда, в виду их неосведомленности, не владения необходимыми навыками поиска работы и ведения переговоров с работодателями.

Исследуя молодежь, стоит уделить внимание теории, разработанной Нейлом Хоувом и Вильямом Штраусом, которые занимались изучением конфликта поколений [Howe 1991]. Именно они обратили внимание на то, что в одном и том же возрасте модели поведения разных поколений совершенно различны. Именно так сформировалась теория X, Y, Z, которая на сегодняшний день находит свое применение в социологии, политологии, экономических и других науках. Данная концепция была построена на исследованиях американского общества, но в дальнейшем применялась для анализа процессов в РФ.

В последнее время в России фриланс получил довольно широкое распространение, а число занятых в данной сфере ежегодно увеличивается. Важным в этом случае является распространение фриланса среди молодежи, так как по результатам многих социологических исследований значительную часть фрилансеров составляет именно она: 58 \% в возрасте от 18 до 30 лет [Стребков, Шевчук, Спирина $2015,105]$. Занятые таким образом молодые люди в основном используют информационные технологии и интернет для своей работы.

\section{Методика \\ социологического исследования}

С целью изучения круга вопросов, связанного с деятельностью фрилансеров, их основными мотивами выбора фриланса как трудовой стратегии, а также существующих проблем и предложений по их решению на базе кафедры философии, социологии и политологии Ульяновского государственного университета было проведено авторское исследование «Фриланс как новая модель занятости на рынке труда», которое имеет следующие технические параметры: срок проведения (февраль-апрель 2018 г.), территория исследования (г. Ульяновск), общее число опрошенных (300 чел.), соотношение респондентов по полу (53 \% мужчин и 47 \% женщин, занимающихся фрилансом и проживающих в городе Ульяновске), выборка (стихийная); метод сбора информации (онлайн-анкетирование). Анкета распространялась через группу «Фрилансеры Ульяновска» в социальной сети «ВКонтакте».

\section{Результаты исследования}

По результатам проведенного исследования было выявлено, что, по мнению фрилансеров, одним из главных преимуществ их деятельности является свобода: свобода в выборе специализации, свобода в распределении времени и нагрузки, свобода передвижения и т. д. Среди недостатков фриланса респонденты отмечают: нестабильность и непредсказуемость будущих доходов (40 \%), отсутствие своего рабочего места, так как дома не всегда удобно работать (37\%), необходимость самому себя организовывать и контролировать $(34 \%)$, самостоятельный поиск новых проектов, заказчиков (31\%), отсутствие коллектива и «живого» общения $(27 \%)$, а также социальных гарантий (27 \%). Одним из главных недостатков респонденты называли нестабильность, проявляющуюся в количестве заказов и заработной плате.

Сегодня наблюдается довольно частое совмещение фриланса с другими видами оплачиваемой или неоплачиваемой занятости. 50 \% опрошенных являются «чистыми» фрилансерами, для которых такой способ заработка является единственным видом занятости. 
Среди остальных опрошенных: $21 \%$ совмещают фриланс с работой в штате организации, $10 \%$ - с учебой, $4 \%$ - с собственным бизнесом, $4 \%$ работают фрилансерами, находясь в декретном отпуске.

По данным Росстата на 2017 г., в России проживает 38970 тыс. молодых людей в возрасте от 15 до 34 лет. Интернет-переписи, проведенные среди фрилансеров России, указывают на то, что молодежь является значительным сегментом среди них. Авторское исследование показывает, что в городе Ульяновске фрилансом занимаются молодые люди в возрасте от 15 до 34 лет - 88 \% респондентов; фрилансеры, возраст которых от 35 лет и старше - $12 \%$ респондентов. При этом $63 \%$ составляют работники не старше 30 лет, а возраст трети всех фрилансеров (36\%)- от 25 до 29 лет.

Гендерных особенностей среди данной группы «самозанятых» не обнаружено. Количество мужчин и женщин практически одинаковое - $53 \%$ и $47 \%$ соответственно. Среди мужчин больше тех, кто совмещает фриланс с работой в штате организации, а среди женщин - тех, кто совмещает фриланс с учебой.

У фрилансеров довольно высокий образовательный уровень: 60 \% опрошенных отмечают, что имеют высшее образование, при этом $5 \%$ из них продолжают обучение в аспирантуре или докторантуре, $16 \%$ - имеют незаконченное высшее образование, $11 \%$ - среднее специальное. Образовательный уровень фрилансеров коррелирует с уровнем заказов: чем выше профессиональный уровень выполняемых работ, тем весомее образовательный ресурс для его осуществления. Однако полученное образование чаще всего не соответствует специализации во фрилансе (34\%).

Основными профессиональными сферами, в которых заняты фрилансеры, являются: копирайтинг (20 \%), дизайн / графика (19\%), разработка и поддержка веб-сайтов (15\%), программирование (15\%).

Среди причин выбора фриланса в качестве занятости респонденты называли: возможность заработать больше денег (39 \%), перерастание хобби в работу (32\%), отсутствие желания работать в качестве сотрудника в штате организации (31 \%), получение профессионального опыта и развитие (17\%). Данный тип занятости наиболее точно отражает ценности поколения Y, представителями которого как раз является современная молодежь. Они могут работать сразу же в нескольких областях, совмещая программирование с дизайном, дизайн с копирайтингом, редактуру с маркетингом, и при этом не испытывать никаких затруднений. Желание молодых людей этого поколения работать сверхурочно и тяга к знаниям приводят к выбору ими фриланса как трудовой стратегии.

$70 \%$ опрошенных удовлетворены своей работой. Респонденты, для которых фриланс единственный вид занятости («чистые» фрилансеры), удовлетворены своей работой в несколько большей степени, чем «совместители».

Возможности ИКТ позволяют фрилансерам работать удаленно и проживать в любом городе России, а заказчиками при этом могут являться работодатели из других регионов и стран. В ходе социологического опроса фрилансеры отмечали, что чаще всего работают с заказчиками из других регионов Российской Федерации (60\% ответивших). С заказчиками из своего региона (Ульяновской области) работают $23 \%$ респондентов; $17 \%$ фрилансеров сотрудничают с заказчиками из других стран. Следовательно, большая часть молодых людей, проживая при этом в г. Ульяновске, работает с заказчиками из других регионов или стран.

Выполняя заказы для клиентов из других регионов РФ, фрилансеры получают возможность больше зарабатывать. По результатам онлайн-опроса, фрилансеры, работающие с заказчиками из своего региона, в среднем имеют доход 20 тыс. руб. в месяц. Те, кто работает с представителями других регионов, имеют средний доход примерно 30 тыс. рублей. При этом доход более 70 тыс. руб. в месяц в основном у фрилансеров, работающих с заказчиками из других стран.

На российском рынке удаленной работы доминируют неформальные отношения. Проведенное исследование показывает, что чаще всего фрилансеры не составляют официальный письменный договор, а просто фиксируют детали работы в ходе переписки с заказчиком (45\%). Четверть ответивших (24\%) используют специальные сервисы бирж уда- 


\section{НАУЧНЫЕ СООБЩЕНИЯ}

ленной занятости и оформление договора происходит с помощью «безопасной сделки»; $18 \%$ респондентов устно обсуждают детали работы, не фиксируя их письменно. Всего лишь $13 \%$ опрошенных составляют официальный письменный договор. Как было отмечено выше, последний чаще всего носит гражданско-правовой характер. Между заказчиком и фрилансером заключается договор найма, договор подряда либо же договор на возмездное оказание услуг. Это говорит о больших рисках фрилансеров при соглашении на выполнение заказа.

Таким образом, можно отметить, что одной из важных составляющих фриланса является доверие. Оно отражает процессы выстраивания взаимодействий в экономической, политической и других сферах, а также в межличностных отношениях. Именно доверие играет значимую роль в социальных отношениях и определяет, насколько успешным будет итог взаимодействия фрилансера с заказчиком, а также снижает необходимость поиска специалистом механизмов для защиты от вероятных рисков. Благодаря уровню доверия определяются механизмы и практики, способствующие развитию карьеры и репутации независимого работника.

Гибкие рыночные отношения создают благоприятные условия для развития неформальной занятости. В России же уровень неформальности и оппортунизма в сфере занятости находится на довольно высоком уровне. Подобного рода отношения на рынке труда способствуют вероятности нарушения прав участников трудовых отношений даже при заключении официального трудового договора. Данные опроса показывают, что 69 \% фрилансеров регулярно сталкивались с нарушениями ранее заключенных договоренностей с заказчиком. При этом $54 \%$ имели дело с задержкой оплаты выполненного заказа, а 49 \% столкнулись с изменениями первоначальных задач и сокращением сроков на выполнение работы.

Сталкиваются с нарушениями первоначальных договоренностей чаще всего фрилансеры, не составляющие официальный письменный договор, но фиксирующие все детали работы в ходе переписки с заказчиком $(34 \%)$. Несмотря на составление офи- циального договора, доля тех, кто столкнулся с нарушениями, в два раза больше тех, кто с ними не сталкивался.

В ходе исследования было выявлено, что многие фрилансеры берут предоплату прежде чем приступать к заказу. При этом поступать таким образом они могут лишь в том случае, когда у них уже были заказы и наработано портфолио. Новичкам очень сложно получить предоплату. Некоторые фрилансеры разбивают задание на несколько частей и просят заказчика оплачивать отдельно каждую часть.

Одной из главных проблем во фрилансе является юридическая и социальная незащищенность работников. Социальная незащищенность заключается в отсутствии каких-либо социальных гарантий у фрилансеров и материальной стабильности. Юридическая незащищенность выражается в сложностях при оформлении сторонами официального трудового договора (или в его отсутствии вообще) и в случаях нарушения со стороны заказчика каких-либо договоренностей, в невозможности отстоять свои права. Отсутствие социального пакета и социальных гарантий, а также легальных, документально подтвержденных доходов в большей степени беспокоит фрилансеров.

Многие фрилансеры сталкиваются с юридическими сложностями при выполнении своей профессиональной деятельности. Заключение договора, оплата налогов являются проблематичными для независимых профессионалов. Фрилансер - это чаще всего физическое лицо, поэтому, выполняя определенную работу, он не выплачивает обязательные налоговые отчисления.

Существующие риски фрилансеров при соглашении на выполнение заказа подтверждаются и результатами коллективного исследовательского проекта «Мониторинг рынка удаленной работы - масштабный количественный онлайн-опрос независимых профессионалов (фрилансеров) и заказчиков их услуг», который реализовала Лаборатория экономико-социологических исследований Национального исследовательского университета «Высшая школа экономики» (далее - НИУ ВШЭ) в рамках Программы фундаментальных исследований НИУ ВШЭ в 2014 г. [Стребков, Шевчук, Спирина 2015, 173]. 


\section{Выводы}

Таким образом, можно сказать, что социально-экономическое пространство современного города - это система социально-экономических отношений и необходимое условие реализации экономических интересов участников на конкретной территории. Для современной молодежи характерно гармоничное сочетание между собой личной жизни, свободного времени и графика работы. Выбор ею трудовой стратегии происходит под влиянием различных факторов, формирующих определенные установки индивида. Выбранная трудовая стратегия может быть следствием определенной ситуации на рынке труда, личного опыта, а также ожиданий (зарплатных или карьерных) соискателя. Помимо этого, на выбор могут влиять личные предпочтения и навыки молодого человека. В связи с этим, выбирая трудовую стратегию, молодежь соотносит приобретенные жизненные установки с возможностями их реализации.

Фриланс как современная форма занятости на рынке труда позволяет молодежи самостоятельно выбирать проект и управлять своим временем, благодаря чему появляется желание самореализовываться и достигать успеха. Однако основной проблемой во фрилансе является социальная и юридическая незащищенность, выражающаяся в отсутствии каких-либо социальных гарантий, материальной стабильности и сложностях при оформлении официального трудового договора. Несмотря на остроту данной проблемы, фрилансеры остаются в секторе неформальной экономики, так как на данный момент такой вид трудовой деятельности не имеет правового регулирования и отсутствует грамотная и гибкая форма налогообложения. Со стороны государственных структур делаются попытки взаимодействия с фрилансерами, выражающиеся в издании новых законов, разработке новой системы налогообложения для самозанятых профессионалов. Результаты авторского исследования показывают, что фрилансеры надеются на скорое решение проблем с правовым регулированием и юридической незащищенностью фриланса. Для вывода фриланса из сектора неформальной экономики и предоставления молодежи возмож- ности выбора данной трудовой стратегии необходима государственная поддержка в правовой сфере, так как это реальная возможность для нее наработать опыт, попробовать себя в разных сферах трудовой деятельности. Кроме того, фриланс - это средство противодействия феномену «утечки умов».

\section{СПИСОК ЛИТЕРАТУРЫ}

Бауман 2005 - Бауман 3. Индивидуализированное общество. М.: Логос, 2005.

Вебер 2012 - Вебер М. Избранное. Образ общества. СПб.: Центр гуманит. инициатив, 2012.

Данилова 2016 - Данилова Е.О. Специфика социально-экономического пространства города: теоретический аспект // Вестник Волгоградского государственного университета. Серия 7 , Философия. Социология и социальные технологии. 2016. № 4 (34). C. 177-182. DOI: https:// doi.org/10.15688/jvolsu7.2016.4.21.

Дюркгейм 1996 - Дюркгейм Э. О разделении общественного труда. М.: Канон, 1996.

Елкина, 2007 - Елкина О.С. Основные закономерности стратегий экономического поведения работников на рынке труда (на основе данных социологических исследований) // Вестник Омского ун-та. 2007. № 1. С. 89-96.

Задорожная 2011 - Задорожная И.И. Молодежь как ресурс неформальной занятости: причины и следствия // Управление мегаполисом. 2011. № 6. C. 79-86.

Кастельс 2000 - Кастельс М. Информационная эпоха: экономика, общество и культур. М.: Эксмо, 2000.

Кастельс 2004 - Кастельс М. Галактика Интернет. Размышления об Интернете, бизнесе и обществе. Екатеринбург: У-Фактория, 2004.

Маркс 1956 - Маркс К. Из ранних произведений. М.: Политиздат, 1956.

Стребков, Шевчук, Спирина 2015 - Стребков Д.О., Шевчук А.В., Спирина, М.О. Развитие русскоязычного рынка удаленной работы, 2009-2014 гг. (по результатам Переписи фрилансеров). М.: ВШЭ, 2015.

Тоффлер 2004 - Тоффлер Э. Третья волна. М.: АСТ, 2004.

Уорнер 1999 - Уорнер Л. Социальный класс и социальная структура // Рубеж. 1999. № 10. С. 42-57.

Чаплашкин 2011 - Чаплашкин Н.В. Социальная сущность фриланса в России и его специфика // Рос. академ. журн. 2011. № 4. С. 13-16.

Howe 1991 - Howe N. Generations: The History of America's Future, 1584 to 2069. N. Y.: William Morrow \& Company: W. Strauss, 1991. 


\section{REFERENCES}

Bauman Z., 2005. An Individualized Society. Moscow, Logos.

Weber M., 2012. Favorites. The Image of Society. Saint Petersburg, Centr gumanitarnyh iniciativ.

Danilova E.O., 2016. The Specifics of the Socio-Economic Space of the City: the Theoretical Aspect. Vestnik Volgogradskogo gosudarstvennogo universiteta. Serija 7, Filosofija. Sociologija i social'nye tehnologii, vol.4 (34), pp. 177-182. DOI: https:// doi.org/10.15688/jvolsu7.2016.4.21.

Durkheim E., 1996. On the Division of Social Labor. Moscow, Kanon.

Elkina O.S., 2007. The Basic Laws of the Strategies of Economic Behavior of Workers in the Labor Market (Based on Sociological Research Data). Vestnik Omskogo Universiteta, vol. 1, pp. 89-96.

Zadorozhnaja I.I., 2011. Youth as a Resource of Informal Employment: Causes and Consequences. Upravlenie megapolisom, vol. 6, pp. 79-86.
Castells M., 2000. The Information Age: Economy, Society and Cultures. Moscow, Eksmo.

Castells M., 2004. Galaxy Internet. Reflections on the Internet, Business and Society, Ekaterinburg, U-Factorija.

Marx K., 1956. From Early Works. Moscow, Politizdat. Strebkov D.O., Shevchuk A.V., Spirina M.O., 2015. Development of the Russian-Language Market of Distant Work, 2009-2014 (According to the Results of the Freelancers Census). Moscow, Vysshaja shkola jekonomiki.

Toffler E., 2004. The Third Wave. Moscow, AST.

Warner L., 1999. Social Class and Social Structure. Rubezh, vol. 10, pp. $42-57$.

Chaplashkin N.V., 2011. The Social Essence of Freelancing in Russia, and its Specificity. Rossijskij akademicheskij zhurnal, vol. 4, pp. 13-16.

Howe N., 1991. Generations: Future, 1584 to 2069. New York, William Morrow \& Company, W. Strauss.

\section{Information About the Authors}

Marina I. Kadnichanskaya, Candidate of Sciences (Sociology), Associate Professor, Department of the Psychology and Pedagogy, Ulyanovsk State University, Lev Tolstoy St., 42, 432017 Ulyanovsk, Russian Federation, m-i-kad@yandex.ru, https://orcid.org/0000-0002-7328-0360

Elena P. Galkina, Candidate of Sciences (Sociology), Associate Professor, Department of the Psychology and Pedagogy, Ulyanovsk State University, Lev Tolstoy St., 42, 432017 Ulyanovsk, Russian Federation,Pyh2000@mail.ru, https://orcid.org/0000-0001-6283-6653

\section{Информация об авторах}

Марина Ивановна Кадничанская, кандидат социологических наук, доцент кафедры психологии и педагогики, Ульяновский государственный университет, ул. Льва Толстого, 42, 432017 г. Ульяновск, Российская Федерация, m-i-kad@yandex.ru, https://orcid.org/0000-0002-7328-0360

Елена Петровна Галкина, кандидат социологических наук, доцент кафедры психологии и педагогики, Ульяновский государственный университет, ул. Льва Толстого, 42, 432017 г. Ульяновск, Российская Федерация, Pуh2000@mail.ru, https://orcid.org/0000-0001-6283-6653 